of at least two of the conventional tests of thyroid function." By choosing only cases in which there was no difficulty in making the clinical diagnosis their series does not give any information on the borderline group of patients in whom the clinical diagnosis is difficult and investigations may also be indecisive. In the present series 97 patients (groups 2, 3, and 4) were in the borderline category because even in those patients clinically diagnosed as probably normal the referring physician had raised the possibility of thyroid dysfunction. From the results shown in Table II it can be seen that there is a better correlation between the jerk times and the ${ }^{131}$ I uptake (77\% agreement) than clinical assessment and either jerk times or the ${ }^{131}$ I uptake. This demonstrates that the jerk times are a useful test in borderline as well as in definite disturbances of thyroid function.

The advantage of this test is its simplicity. It is inexpensive and the results are immediately available. Useful information can be obtained in patients in whom ${ }^{131} \mathrm{I}$ studies are unsatisfactory or difficult to interpret ; for example, after treatment with radioactive iodine, or thyroidectomy, with antithyroid drugs or sulphonylureas; if the patient has been ingesting large doses of iodine, as in some cough mixtures; or after contrast radiography. It may be used in pregnancy or in situations where ${ }^{131}$ I facilities are not available. The main advantage is that it is an objective guide to the efficacy of therapy in both hypothyroid and thyrotoxic subjects.

Apart from the drugs already mentioned high doses of salicylates, dexamphetamine, A.C.T.H. and steroids, and oestrogens are said to shorten the duration of the jerk times (Lawson, 1958).

Muscle disorders such as dystrophia myotonica have been observed to shorten the jerk times (Lambert et al., 1951), and sarcoidosis (Richards, 1962) and neurosyphilis (Simpson et al., 1963) may prolong them.

Disturbances of the central nervous system may alter the amplitude of the jerks but do not alter the times in some conditions (Sherman et al., 1963). However, in view of the changes observed in neurosyphilis the interpretation of jerk times in patients with organic neurological disease must be tentative.

\section{Summary}

The ankle-jerk has been measured with the method described by Smart and Robson (1963). The results recorded from 131 subjects gave a normal range of $145-230 \mathrm{msec}$. and $240-340$ msec. for the tap-to-peak and tap-to-half-relaxation measurements respectively.

The ankle-jerk times obtained in 165 patients with thyroid disease are compared with an independent clinical assessment and with the neck uptake of radioactive iodine (interpreted in conjunction with the protein-bound radioactive iodine).

Both the contraction and the relaxation phases of the anklejerks are affected by thyroid hormones, either measurement being equally satisfactory for use in the assessment and management of thyroid disease. This is illustrated by reference to the jerk times in a patient with thyrotoxicosis, in one with panhypopituitarism, and in three normal subjects after the administration of triiodothyronine.

The limitations of the test are discussed, and it is concluded that the test is a simple inexpensive way of diagnosis and the only objective means, apart from the B.M.R., of assessing response to treatment.

We wish to express our thanks to Dr. D. Taverner and Dr. C. J. Hayter for their help and criticisms. We also thank Mr. B. Harvey for his technical assistance.

\section{REFERENCES}

Buller, A. J. (1963). Lancet, 1, 443.

Fogel, R. L., Epstein, J. A., Stopak, J. H., and Kupperman, H. S. (1962). N.Y. St. Epstein, J. A., Stopak

N.Y. St. F. Med., 62, 1159. . O., Beckett, S., and Mederos, L. O. (1951). f. clin. Endocr., 11, 1186.

Lawson, J. D. (1958). New Engl. ₹. Med., 259, 761.

Richards, A. G. (1962). Canad. med. Ass. 7., 86, 32

Sherman, L., Goldberg, M., and Larson, F. C. (1963). Lancet, 1, 243. Simpson, G. M., Blair, J. H., and Nartowicz, G. R. (1963). New Engl. 7. Med., 268, 89.

Smart, G. A., and Robson, A. M. (1963). Lancet, 1, 363.

\title{
Effect of Variation in Dietary Calcium on Plasma Concentration and Urinary Excretion of Calcium
}

\author{
I. J. MACFADYEN, ${ }^{*}$ M.B., CH.B., D.oBsT.R.C.O.G. ; B. E. C. NORDIN, $\dagger$ M.D., PH.D., M.R.C.P. ; \\ D. A. SMITH, $\ddagger$ M.B., CH.B., B.SC., M.R.C.P.ED. ; D. J. WAYNE,*\| M.A., B.M., B.CH., M.R.C.P., M.R.C.P.ED. ; \\ S. L. RAE, F.I.M.L.T.
}

Brit. med. F., 1965, 1, 161-164

The constancy of the plasma calcium in normal persons despite wide variations in calcium intake is well recognized, and early suggestions that it could be influenced by dietary intake have been largely discounted (Smith, Davis, and Fourman, 1960 ; Nordin, 1961). The urinary calcium, on the other hand, unlike the plasma calcium, is well known to be influenced by dietary intake, although the variation from one individual

\footnotetext{
* Research Assistant, University Department of Medicine, Gardiner Institute, Western Infirmary, Glasgow.

† Senior Lecturer, University Department of Medicine, Gardiner Institute, Western Infirmary, Glasgow. Present address: M.R.C Mineral Metabolism Research Unit, General Infirmary, Leeds.

₹ Temporary Lecturer, University Department of Medicine, Gardiner Institute, Western Infirmary, Glasgow.

$\$$ Chief Technician, University Department of Medicine, Gardiner Institute, Western Infirmary, Glasgow.

|| Present address : University College Hospital, London.
}

to another on the same intake is large (Knapp, 1947) and the normal range of urinary calcium on a free diet or even on a low-calcium diet is relatively wide (Hodgkinson and Pyrah, 1958). It has not been clear how the changes in urinary calcium are brought about by variations in dietary calcium, but one possibility is that they are due to small changes in the filtered load of calcium. Consideration of the magnitude of the filtered load of calcium (about $7 \mathrm{~g}$. daily) and its relation to calcium excretion (about $200 \mathrm{mg}$. daily) indicates that very small changes in the concentration of the plasma ultrafilterable calcium (too small to be detected by routine laboratory methods) could easily account for the variations in urinary calcium normally encountered. The present work was therefore planned to test the possibility that the alteration in urinary calcium brought about by changing from a normal to a low 
intake of calcium (or vice versa) might be attributable to a small change in the calcium concentration of the plasma.

\section{Methods}

Subjects Studied.-Fifty-eight subjects were studied: 11 were members of the staff and 47 were in-patients. Of the 47 inpatients, 11 were cases of osteoporosis, one was a case of osteomalacia, and 35 had miscellaneous disorders not connected with calcium metabolism, but agreed to the studies being performed. One patient and three members of the staff were studied twice, making a total of 62 studies in all.

\section{Procedure}

In preliminary observations on 11 non-osteoporotic patients without any disorder of calcium metabolism, calcium excretion was determined in three 24-hour collections of urine on the ward diet followed by nine on a low-calcium diet containing about $250 \mathrm{mg}$. of calcium and $500 \mathrm{mg}$. of phosphorus.

In the next 40 studies ( 27 of the subjects having no disorder of calcium metabolism, 24 being patients and three members of the staff) blood samples were taken at 9.30 a.m. and 12.30 , 2.30 , and 4.30 p.m. on two successive days, making eight samples in all from every subject except two from whom only six samples were taken. Urine was collected on both days and calcium excretion determined. In these studies the diets were given as follows: in 19 the ward diet was given on the first day and the low-calcium diet on the second ; in 21 the lowcalcium diet was given on both days but was supplemented with calcium lactate on the first day (in 17) or the second day (in four) to make a total calcium intake of about $1,200 \mathrm{mg}$.

In a final series of studies 11 members of the staff took a lowcalcium diet for two days and ate $1 \mathrm{~g}$. of calcium as calcium lactate on the first day. Blood was taken from them at 9 a.m. and 12 noon on each day for determination of the ultrafilterable calcium.

Thus in 47 of the 51 plasma studies the regime changed from an average to a low-calcium intake and in four from a low to an average level. In 32 of these 51 studies the only change in the diet was its calcium content.

\section{Biochemical Methods}

Serum and urine calcium were estimated by an AutoAnalyzer (Technicon Instruments) with the following modifications to the standard technique :

1. The alkaline buffer line has an internal diameter of 0.056 in. $(1.46 \mathrm{~mm}$.) (yellow) instead of $0.045 \mathrm{in} .(1.14 \mathrm{~mm}$.) (red), giving a delivery of $1.2 \mathrm{ml} . /$ minute instead of $0.8 \mathrm{ml}$.

2. A 40 -foot (12-metre) time-delay coil in a water-bath at room temperature was introduced before the colorimeter.

3. The working standards were made up in $0.15 \mathrm{M}$ sodium chloride.

4. A range expander (Heathkit resistance box) was placed in series with the negative side of the reference photo cell in the recorder.

5. The calcium-releasing agent (hyamine and acetate buffer) was adjusted to $p \mathrm{H} 4$ instead of $p \mathrm{H} 5$.

6. The ammonium purpurate solution was adjusted to $p \mathrm{H} 7$ by adding diethylamine.

7. Urine dilutions were made with $0.15 \mathrm{M}$ sodium chloride.

Ultrafiltration was performed on fresh serum transferred to Cellophane tubing without exposure to the atmosphere and centrifuged at $37^{\circ} \mathrm{C}$. for one hour at $2,000 \mathrm{~g}$ in tubes similar to those devised by Toribara, Terepka, and Dewey (1957). The calcium was measured by the AutoAnalyzer technique described above.

\section{Results}

The effect of the low-calcium diet on the 24-hour urine calcium in 11 subjects is shown in Fig. 1. The mean calcium excretion fell from $243.2 \mathrm{mg}$. on the third day of the ward diet to $179.1 \mathrm{mg}$. on the first day of the low-calcium diet. There was little further fall in the next nine days.

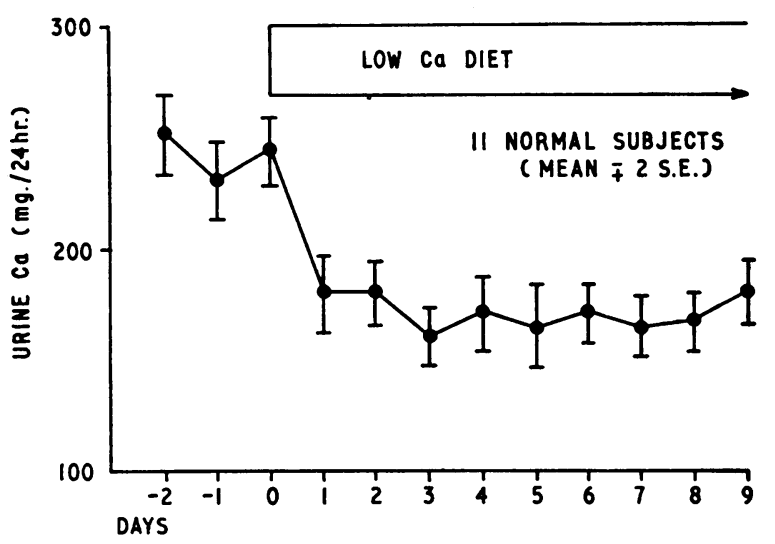

FIG. 1.- Mean urinary calcium excretion in 11 normal subjects during three days on a ward diet and nine days on a lowcalcium diet.

The results of 27 blood and urine studies in patients without disorders of calcium metabolism are shown in Table $\mathrm{I}$. The mean plasma calcium on the ward diet was $9.46 \mathrm{mg} . / 100 \mathrm{ml}$. and on the low-calcium diet $9.29 \mathrm{mg}$. The difference, although small, is significant. The mean urinary calcium excretion in these 27 subjects was $198.8 \mathrm{mg}$. on the normal calcium intake and $135.7 \mathrm{mg}$. on the low calcium intake. The difference of $63.1 \mathrm{mg}$. is significant (Table II), $\mathrm{P}$ being less than 0.02 . The mean calcium/creatinine ratios were 0.17 and 0.12 respectively, and this difference is also significant (Table III), $\mathbf{P}$ being less than 0.02 .

TABle I.-Plasma Calcium on Normal and Low-calcium Diets

\begin{tabular}{c|c|c|c|c}
\hline Diet & $\begin{array}{c}\text { No. of } \\
\text { Subjects }\end{array}$ & $\begin{array}{c}\text { No. of } \\
\text { Observations }\end{array}$ & $\begin{array}{c}\text { Mean Plasma } \\
\text { Calcium } \\
(\mathrm{mg./100} \mathrm{ml.})\end{array}$ & S.E. \\
\hline $\begin{array}{l}\text { Normal _. } \\
\text { Low-calcium }\end{array}$ & 27 & 108 & $\begin{array}{l}9 \cdot 46 * \\
9 \cdot 29 *\end{array}$ & $\begin{array}{l}0.046 \\
0.043\end{array}$ \\
\hline
\end{tabular}

* Difference between the means $=0.17 ; \mathrm{t}=2.6 ; \mathrm{P}<0.01$.

TABLE II.-24-Hour Urine Calcium on Normal and Low-calcium Diets

\begin{tabular}{c|c|c|c|c}
\hline \multicolumn{1}{c|}{ Diet } & $\begin{array}{c}\text { No. of } \\
\text { Subjects }\end{array}$ & $\begin{array}{c}\text { No. of } \\
\text { Observations }\end{array}$ & $\begin{array}{c}\text { Mean 24-hour } \\
\text { Urine Calcium }\end{array}$ & S.E. \\
\cline { 2 - 4 } Normal $\cdots$ & 27 & 27 & $198 \cdot 8^{*}$ & $\begin{array}{c}21 \cdot 3 \\
135 \cdot 7^{*}\end{array}$ \\
\hline
\end{tabular}

* Difference between means $=63.1 ; t=2.5 ; \mathrm{P}<0.02$.

TABLE III.-Urine Calcium/Creatinine Ratio on Normal and Lorv-

\begin{tabular}{c|c|c|c|c}
\multicolumn{1}{c|}{ calcium diets } \\
\hline Diet & $\begin{array}{c}\text { No. of } \\
\text { Subjects }\end{array}$ & $\begin{array}{c}\text { No. of } \\
\text { Observations }\end{array}$ & $\begin{array}{c}\text { Mean Urine } \\
\text { Ca/Cr }\end{array}$ & S.E. \\
\hline Normal $\ldots$ & 27 & 27 & $\begin{array}{c}0 \cdot 17^{*} \\
0 \cdot 12^{*}\end{array}$ & $\begin{array}{c}0.016 \\
0.013\end{array}$ \\
\hline Low-calcium & 27 & 27 &
\end{tabular}

* Difference between means $=0.05 ; \mathrm{t}=2.5 ; \mathrm{P}<0.02$.

The ultrafilterable calcium concentrations in 11 members of the staff on the normal and low calcium intakes are shown in Fig. 2. The mean calcium concentration on the normal intake was $5.56 \mathrm{mg} . / 100 \mathrm{ml}$. and on the low intake $5.23 \mathrm{mg}$. The difference is highly significant $(\mathrm{t}=3.9 ; \mathrm{P}<0.001)$. Fig. 3 shows part of the AutoAnalyzer tracing obtained when these ultrafilterable calcium concentrations were determined. The samples obtained on the two diets were fed in alternately and the difference in peak heights is clearly visible. 
In considering the relation between plasma and urine calcium the data from all the subjects (including cases of osteoporosis and osteomalacia) have been included. There was no correlation between the absolute plasma-calcium concentration and the

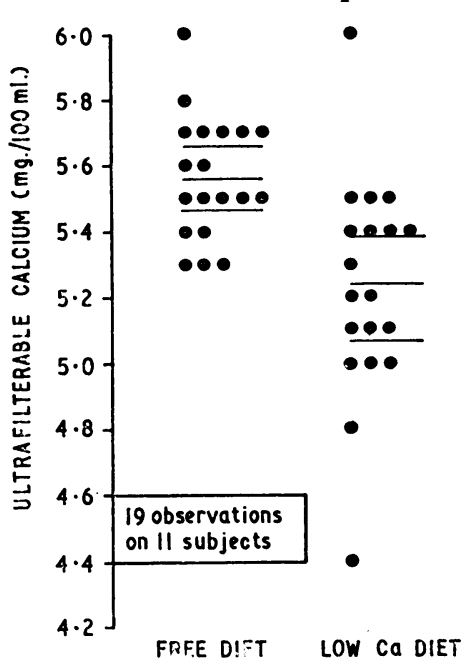

FIG. 2.-Ultrafilterable calcium concentrations in 11 normal subjects on an approximately normal calcium intake (left) and on the following day on a low calcium intake (right). absolute calcium excretion, but there was a significant correlation between the change in plasma calcium and the change in urine calcium $(\mathrm{r}=0.46 ; \quad \mathrm{P}<0.005)$ (Fig. 4). There was a slightly better correlation between the change in plasma calcium and the change in urinary calcium/creatinine ratio (Table IV).

\section{Discussion}

We have demonstrated a small but significant difference between the mean plasma - calcium concentrations in 27 subjects on normal and low-calcium diets. Though very small, this difference is more than enough to account for the effect of the change in dietary intake on urinary calcium. In fact, the relation between the plasma and urinary calcium changes is such as to suggest that the tubular maximum reabsorptive capacity for calcium (if such a maximum exists) was not exceeded in this group of subjects as a whole. Thus if one assumes that the ultrafilterable calcium is $53 \%$ of the total plasma calcium (Walser, 1961), then the observed mean change of $0.18 \mathrm{mg}$./ $100 \mathrm{ml}$. in calcium corresponds to a change of $0.1 \mathrm{mg} . / 100 \mathrm{ml}$. in the ultrafilterable calcium concentration. At a glomerular filtration rate of $100 \mathrm{ml} . /$ minute this could account for a change in urinary calcium excretion of $144 \mathrm{mg}$./day if tubular reabsorption remained constant (Fig. 4), compared with the observed change of $63.1 \mathrm{mg}$. (Table II).

These observations have been made possible by the use of an automated procedure for calcium estimation which eliminates the majority of the human errors in laboratory work (pipetting, titrating, and the like). In order to reduce the possibility of error to a minimum most of the samples were put through the AutoAnalyzer in batches of eight, and in many the plasma or ultrafiltrate samples from the two days of the study were fed in alternately. The difference in the heights of the peaks on the normal and low-calcium diet days was clearly visible, as shown in Fig. 3.

We cannot say whether it is the ionic or complexed fraction of the calcium which is primarily involved in the changes we

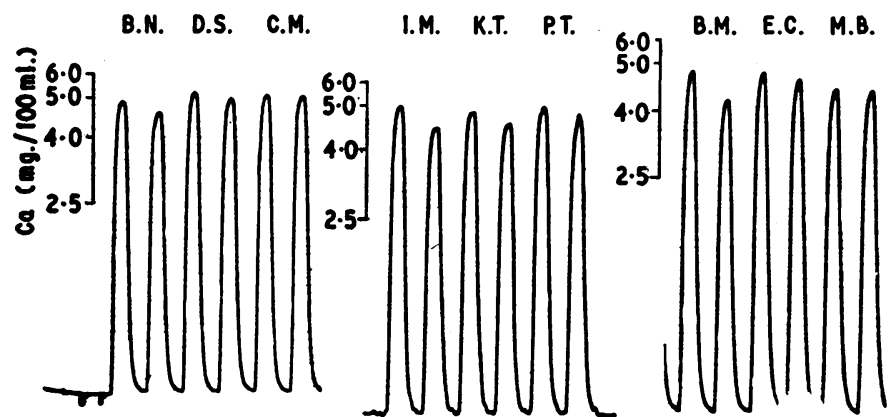

Fig. 3.-AutoAnalyzer tracings of ultrafilterable calcium in nine normal subjects on an approximately normal calcium intake and on a low calcium Intake. The right tracing of each pair is on the low-calcium diet. It is lower than the left-hand tracing in seven cases out of nine and equal in have observed, nor whether these changes have any effect upon the parathyroid glands. We have previously reviewed the evidence which suggests that low-calcium diets do not stimulate the parathyroid glands whereas high-phosphate diets do (Nordin, 1960, 1961), but we now find that the two procedures produce an almost identical fall in plasma calcium (Smith and Nordin, 1964). High-phosphate feeding produces a rise in the phosphate-excretion index (P.E.I.) which is suppressible by calcium infusion, and this strongly suggests parathyroid stimulation (Smith and Nordin, 1964). Low-calcium diets, however, do not have any effect on the P.E.I. (Nordin, 1964). Furthermore, Stoerk and Carnes (1945) have shown that high-phosphate diets cause an increase in parathyroid weight in animals. Crawford et al. (1957) have shown, on the other hand, that low-calcium diets do not cause parathyroid hyperplasia so long as the diets are not deficient in vitamin $\mathrm{D}$. Why comparable changes in plasma calcium should apparently have different effects upon the parathyroid glands is. far from clear, but it could be that the calcium fraction involved is different in the two situations or that our assessment of parathyroid-gland activity is inadequate. This is evidently a problem which deserves further study.

\section{Summary}

In 11 patients without disorders of calcium metabolism the urine calcium fell from 243 to $179 \mathrm{mg}$. on the first day of a low-calcium diet.

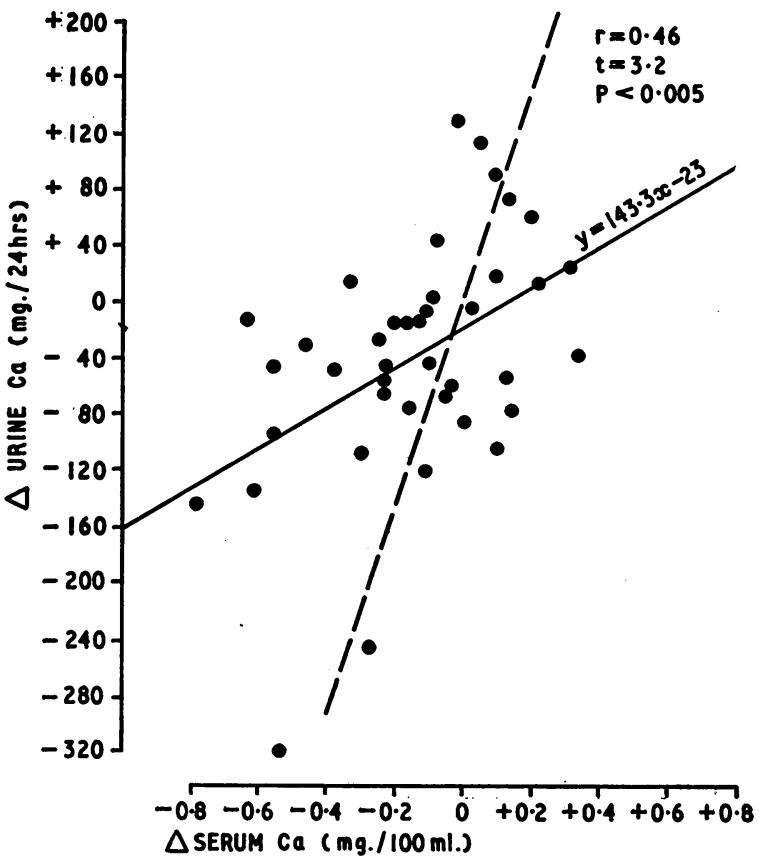

FIG. 4.-Relation between change in urinary calcium and change in plasma calcium in $\mathbf{4 0}$ subjects going from a normal to a low calcium intake or vice versa. The interrupted line to a represents the theoretical relation which would operate at a glomerular filtration rate of $100 \mathrm{ml}$./minute and $50 \%$ ultrafilterable calcium if the maximum tubular reabsorptive capacity for calcium were exceeded.

TABLE IV.-Relation of Change in Urinary Calcium to Change in Serum Calcium

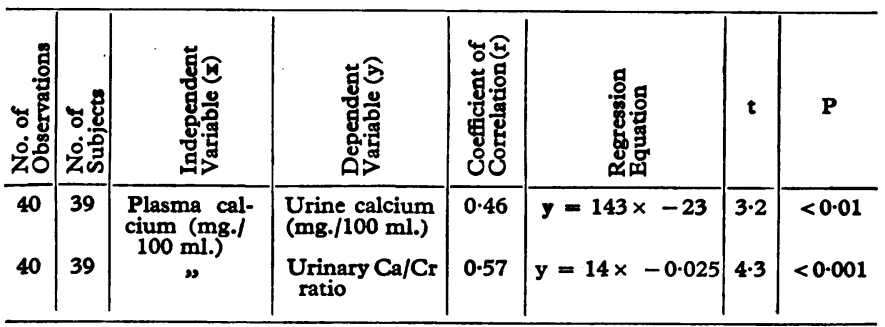


In 27 subjects without any disorder of calcium metabolism the plasma calcium, measured four times daily, was significantly reduced when the calcium intake was reduced. The urine calcium also fell significantly.

Eleven normal subjects received a normal and a low-calcium diet on successive days. The ultrafilterable calcium fell significantly on the day of the low calcium intake.

There was a significant correlation between the changes in the plasma and urinary calcium produced by the alteration in the calcium intake. The relative magnitude suggests that if a maximum tubular reabsorptive capacity for calcium exists it was not exceeded under the conditions of these observations.

Thus it would appear that changes in urine calcium brought about by variations in calcium intake could be accounted for by small but significant changes in plasma ultrafilterable calcium.

REFERENCES

Crawford, J. D., Gribetz, D., Diner, W. C., Hurst, P., and Castleman, B. (1957). Endocrinology, 61, 59.

Hodgkinson, A., and Pyrah, L. N. (1958). Brit. F. Surg., 46, 10

Knapp, E. L. (1947). Ұ. clin. Invest., 26, 182.

Nordin, B. E. C. (1960). Clin. Orthop., 17, 235.

- (1961). Advanc. clin. Chem., 4, 275.

(1964). In The Scientific Basis of Medicine: Annual Reviews, 308. Athlone Press, London.

Smith, D. A., and Nordin, B. E. C. (1964). Clin. Sci., 26, 479.

Smith, J. W.' G., Davis, R. H., and Fourman, P (1960), Lancet, 2, 510

Smith, J. A. G., Davis, R. W., H. (1945). \%, Nu (1960). 29 anc

Toribara, T., Y., Terepka, A. R., and Dewey, P. A. (1957). f. clin. Invest., 36, 738 .

Walser, M. (1961). Ibid., 40, 723.

\title{
Renal Artery Stenosis, Hypertension, and Polycythaemia
}

\author{
R. G. LUKE,* M.B., CH.B., M.R.C.P., M.R.C.P.ED. ; A. C. KENNEDY,* M.D., F.R.C.P.ED., F.R.C.P.GLASG. ; \\ W. BARR STIRLING, $\dagger$ CH.M., F.R.C.S.ED. ; F.R.C.S.GLASG.; G. A. MCDONALD, $\ddagger$ M.D., M.C.PATH.
}

Brit. med. F., 1965, 1, 164-166

The association, which in many cases has proved to be a causative one, between renal disease and polycythaemia is now well recognized (Brandt et al., 1963). Reversion of blood values to normal has been demonstrated after removal of hypernephroma (Conley et al., 1957 ; Damon et al., 1958), unilateral polycystic kidney (Jones et al., 1960), hydronephrotic kidney (Cooper and Tuttle, 1957), and a simple renal cyst (Nixon et al., 1960). The great majority of cases described have been in association with neoplastic renal disease (Nixon et al., 1960 ; Jones et al., 1960). It has been suggested (Penington, 1962) that in non-neoplastic renal disease the mechanism of production of the polycythaemia depends on nephrons responding to decreased perfusion by increased production of erythropoietin, a mucoprotein hormone which stimulates erythropoiesis.

We report here a case of renal artery stenosis with severe hypertension and polycythaemia ; after nephrectomy the bloodpressure returned to near normal and blood values returned to complete normality. So far as we are aware this is the first record of the association of polycythaemia with renal ischaemia due to disease of the extrarenal vasculature and of its cure by nephrectomy.

\section{Case Report}

The patient, a man aged 54, of average build, was well until two months before admission (on 21 January 1964), when he developed headache, general malaise, visual impairment, and nocturia. His family history was negative for hypertension, both parents dying at the age of 74, and the past history was unhelpful. The bloodpressure was $240 / 140 \mathrm{~mm}$. $\mathrm{Hg}$, and the fundi showed exudates and haemorrhages and early papilloedema. There was a trace of proteinuria. No abdominal bruit was heard. Culture of the urine was sterile and the blood urea was $24 \mathrm{mg} . / 100 \mathrm{ml}$. Twenty-fourhour endogenous creatinine clearance was $86 \mathrm{ml} . /$ minute. An electrocardiogram was negative. Chest $x$-ray examination showed clear lung fields and some arteriosclerotic change in the aorta without left ventricular hypertrophy. While investigations to exclude renovascular hypertension were undertaken, his hypertension was

* Department of Medicine, the Royal Infirmary, Glasgow.

† Department of Urology, the Royal Infirmary, Glasgow.

$¥$ Department of Haematology, the Royal Infirmary, Glasgow. treated by methyldopa with only partial response; although there was marked visual and fundal improvement with a dose of 2.5 g./day, blood-pressure averaged 190/120 mm. Hg lying and 150/100 $\mathrm{mm}$. $\mathrm{Hg}$ standing even under hospital conditions.

Renal Investigation.-The intravenous pyelogram showed marked disparity in parenchymal mass, the long axis of the right kidney being $9 \mathrm{~cm}$. compared with $13.2 \mathrm{~cm}$. on the left side. The left kidney appeared hypertrophied, with normal caliceal outline, but

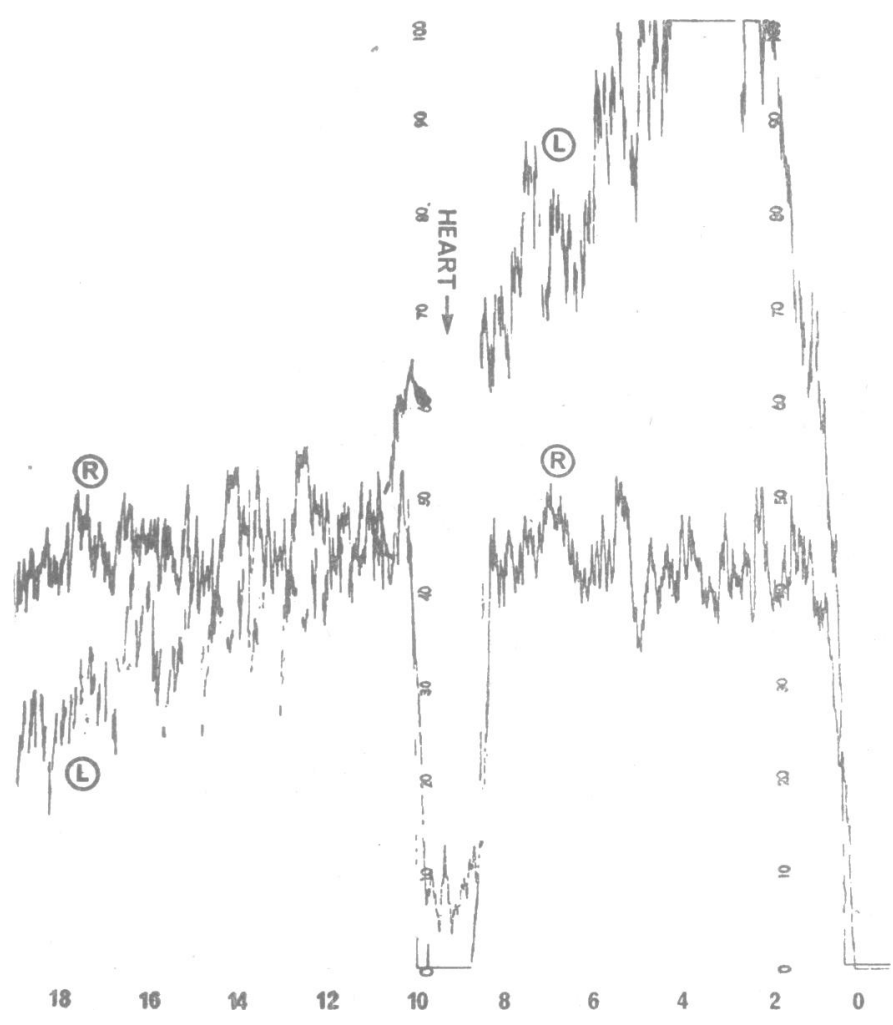

FIG. 1.-Isotope renogram showing normal curve on left side and diminution in vascular and tubular secretory phases on right side and flattening of excretory phase. 